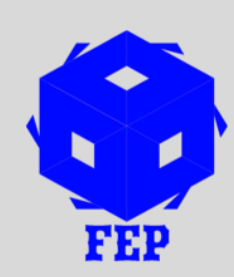

\title{
ASSESSMENT OF SOME HEAVY METALS IN SOME CHOCOLATE BRANDS AND BREAD SOLD IN MAIDUGURI, BORNO STATE, NIGERIA
}

\author{
${ }^{1}$ A. I. Mohammed, ${ }^{2}$ A. A. Ahmed, ${ }^{3}$ T. Lot, $\&{ }^{4}$ M. Solomon \\ ${ }^{1,2,3,4}$ Department of Pure and Applied Chemistry, University of Maiduguri, PMB 1069, \\ Maiduguri, Borno State, Nigeria
}

*Corresponding Author: A. I. Mohammed

Article Received: 20-10-20 Accepted: 11-11-20

Published: $30-11-20$

Licensing Details: Author retains the right of this article. The article is distributed under the terms of the Creative Commons Attribution-NonCommercial 4.0 License (http://www.creativecommons.org/licences/by-nc/4.0/) which permits non-commercial use, reproduction and distribution of the work without further permission provided the original work is attributed as specified on the Journal open access page.

\section{ABSTRACT}

Three brands of chocolate and five varieties of bread samples were collected and subjected to acid digestion for evaluation of some heavy metals $(\mathrm{Cu}, \mathrm{Cr}, \mathrm{Pb}, \mathrm{Fe}, \mathrm{Cd}$ and $\mathrm{Zn})$ using atomic absorption spectrophotometry. The concentrations of the studied heavy metals in the chocolate brands were in the range $0.02-0.20 ; 0.02-0.10$ and $0.09-0.20 \mathrm{mg} / \mathrm{kg}$ for $\mathrm{Cd}, \mathrm{Zn}$ and $\mathrm{Cr}$ respectively. whereas $\mathrm{Pb}$ was not detected in the study. As per the bread samples, the concentrations ranged $0.05-0.13 ; 0.60-2.24,0.30-0.06$ and $0.02-0.10 \mathrm{mg} / \mathrm{kg}$ for $\mathrm{Cd}, \mathrm{Zn}, \mathrm{Cr}$ and $\mathrm{Pb}$ respectively. This study indicates that the concentrations of the studied brands of chocolate and bread are within the allowable limits hence pose no potential health risk or hazard upon consumption.

Keywords: Chocolate, Concentrations, Spectrometry, Acid digestion

\section{INTRODUCTION}

Heavy metals refer to metals or semi-metals with densities more than $5 \mathrm{gcm}^{-1}$ and atomic weight of $63.546-200.590 \mathrm{~g}$ which have the specific gravity of 4.0. In concentrations above the critical threshold, they are toxic for organisms. However, some of them such as Fe, Mn, $\mathrm{Cu}, \mathrm{Zn}$ and $\mathrm{Se}$ in lower concentrations are essential for metabolic processes (Ikem and Egiebor, 2005).

Chocolate is a sweet, confectionery of Theobroma cacao seeds. It is one of the common consumables by all age groups (Dias and Wickramasinghe, 2016). Chocolate is regularly eaten for gratification. There are potential beneficial health effects of eating chocolate; the 
unconstrained consumption of large quantities of any energy-rich food such as chocolate without a corresponding increase in activity could increase the risk of obesity and dental complications. Contamination of food products with heavy metals have capability to cause serious health risks. This is because, consumption of foods with even a low concentration of the heavy metals can result to considerable concentrations in the human body leading to biotoxic effects (Dias and Wickramasinghe, 2016).

This study is aimed at evaluating levels of some heavy metals ( $\mathrm{Pb}, \mathrm{Cd}, \mathrm{Cr}$ and $\mathrm{Zn}$ ) in chocolates and breads samples sold in Maiduguri, Borno State, Nigeria.

\section{MATERIALS AND METHODS}

All reagents used were of analytical grade and used as supplied without further purification. Atomic absorption spectrophotometer 210 VGP was used for determination of the concentration of heavy metals in the samples.

\section{Sample Collection}

Three selected brands of chocolates labelled sample A, B and C were collected from Gidan Madara, Maiduguri, Borno State.

The Bread samples were collected from different bakeries in Maiduguri, Borno State and stored in a polythene bag and conveyed directly to the chemistry research laboratory for further analyses.

\section{Sample Preparation by Acid Digestion \\ Digestion of Chocolates}

$2 \mathrm{~g}$ of each of the chocolate samples was weighed into $250 \mathrm{ml}$ beaker, $10 \mathrm{ml}$ of aqua regia (mixture concentrated $\mathrm{HCl}$ and $\mathrm{HNO}_{3}$ in ratio 3:1). The mixture was heated for 30 minutes, removed and cooled, then $10 \mathrm{ml}$ of $30 \%$ hydrogen peroxide $\left(\mathrm{H}_{2} \mathrm{O}_{2}\right)$ was gently added to avoid any possible overflow leading to loss of material from the beaker. The beaker wall and watch glass were washed with distilled water. The sample was continuously heated until the volumes reduced to $5 \mathrm{ml}$. Then the solution was filtered to remove the insoluble materials and made up to the mark in a volumetric flask (Radojevic and Bashkin, 1999; Akan et al., 2010).

\section{Ashing and Digestion of Bread Samples}

The bread samples were placed in a porcelain crucible and put into muffler furnace and the temperature was raised to $400{ }^{0} \mathrm{C}$ for about three hours. After the sample has been ashed, it was removed and cooled in a desiccator for further analysis.

$0.5 \mathrm{~g}$ of the ashed sample was weighed into $250 \mathrm{ml}$ beaker. $10 \mathrm{ml}$ of $6 \mathrm{M}$ hydrochloric acid was added. The mixture was heated for 15 minutes, was removed and cooled. $1 \mathrm{ml}$ of concentrated nitric acid was added and the sample was again heated to evaporate to dryness to dehydrate the silica.

$1 \mathrm{ml}$ of $6 \mathrm{M}$ Hydrochloric acid was added, followed by $10 \mathrm{ml}$ of distilled water and heated again to dissolution. Then it was left to cool and then filtered with Whatman filter paper into volumetric flask, diluted to the mark with distilled water and transferred into a white bottle for further analysis.

\section{Estimation of Daily Dietary Intake (DIM)}

To assess the risk associated with consumption of the studied products, estimated daily intake of each metal (DIM) was calculated by using the relation: 


$$
D I M=\frac{\text { Cmetal } x \text { Wfood }}{B W}
$$

Where

$\mathrm{C}_{\text {metal }}=$ concentration of heavy metals in the samples in $\mathrm{mg} / \mathrm{g}$

$\mathrm{W}_{\text {food }}=$ daily average weight of the sample consumed (assumed $20 \mathrm{~g}$ and $100 \mathrm{~g}$ of each sample is taken by children and adult respectively)

$\mathrm{B}_{\mathrm{w}}=$ body weight assuming that samples are consumed by children and adult with average body weight of $20 \mathrm{~kg}$ and $70 \mathrm{~kg}$ respectively)

(Lanre-Iyanda and Adekunle, 2012; Ochu et al., 2012)

\section{RESULTS AND DISCUSSION}

The concentrations of the heavy metals $(\mathrm{Pb}, \mathrm{Cd}, \mathrm{Cr}$ and $\mathrm{Zn})$ in some chocolate brands sold in the markets of Maiduguri, Borno State, Nigeria were determined by Atomic absorption spectrophotometer. The results are presented in Table 1. From the results obtained, $\mathrm{Pb}$ was not detected in the three brands of the chocolates analyzed. The levels of $\mathrm{Cd}$ ranged between $0.10-0.20 \mathrm{mg} / \mathrm{L}$ with brand A having the highest concentration of $0.20 \mathrm{mg} / \mathrm{L}$ and least concentration of $0.10 \mathrm{mg} / \mathrm{L}$ for brand $\mathrm{B}$. The concentrations of $\mathrm{Zn}$ and $\mathrm{Cr}$ ranged between $0.02-0.10 \mathrm{mg} / \mathrm{L}$ and $0.09-0.20 \mathrm{mg} / \mathrm{L}$ respectively. These concentrations are higher than those reported by Iwegbue (2011) and Ochu et al, 2012. The results are also in line with that reported by Dias and Wickramasinghe (2016). All the found concentrations of the studied heavy metals in the different brands of chocolate are within the allowable limits for consumption.

Table 1

Mean concentrations $(\mathrm{mg} / \mathrm{kg})$ of some heavy metals found in some selected brands of chocolates.

\begin{tabular}{lllll}
\hline \multirow{2}{*}{ Brands } & \multicolumn{4}{l}{ Concentration of heavy metals $(\mathrm{mg} / \mathrm{kg})$} \\
& Pb & Cd & Zn & $\mathbf{C r}$ \\
& & & & \\
\hline A & ND & 0.20 & 0.02 & 0.20 \\
B & ND & 0.02 & 0.10 & 0.09 \\
C & ND & 0.10 & 0.10 & 0.10 \\
WHO Limit & 0.24 & 0.44 & 1.40 & 0.11 \\
\hline
\end{tabular}

ND= Not detected

Table 2

Estimated daily Intake of Heavy metals (DIM) from Chocolate brands for Children and Adults in $\mathrm{mg} / \mathrm{kg}$

\begin{tabular}{|c|c|c|c|c|c|c|c|c|}
\hline \multirow[t]{2}{*}{ Brands } & \multicolumn{5}{|c|}{ DIM (mg/kg) for Children } & \multicolumn{3}{|c|}{ DIM (mg/kg) for Adult } \\
\hline & $\mathbf{P b}$ & Cd & $\mathbf{Z n}$ & $\mathrm{Cr}$ & $\mathbf{P b}$ & Cd & $\mathbf{Z n}$ & $\mathrm{Cr}$ \\
\hline $\mathbf{A}$ & NA & 0.20 & 0.02 & 0.20 & NA & 0.285 & 0.029 & 0.285 \\
\hline $\mathbf{B}$ & NA & 0.02 & 0.10 & 0.09 & NA & 0.090 & 0.142 & 0.129 \\
\hline $\mathbf{C}$ & NA & 0.10 & 0.10 & 0.10 & NA & 0.142 & 0.142 & 0.142 \\
\hline
\end{tabular}

NA: Not applicable 
Heavy metals can enter crops and eventually bread. Flour can also be contaminated with heavy metals when contaminated water is used in preparation of the dough (Hashemi et al, 2017). Furthermore, location of bakeries and their proximity to industrial sites and fuel types used are of paramount importance in deposition of heavy metals in bread (Shahryari and Mollasadeghi, 2011). The ingestion of these metals could be detrimental to human health especially when they occur in high concentration.

Table 3

Mean Concentration $(\mathrm{mg} / \mathrm{kg})$ of Heavy Metals in Bread Samples Compared with FAO/WHO standard.

\begin{tabular}{lllll}
\hline \multirow{2}{*}{ Samples } & \multicolumn{4}{l}{ Concentration of heavy metals $(\mathbf{m g} / \mathbf{k g})$} \\
\cline { 2 - 5 } & $\mathbf{P b}$ & $\mathbf{C d}$ & $\mathbf{Z n}$ & $\mathbf{C r}$ \\
\hline $\mathbf{A}$ & & & & \\
$\mathbf{B}$ & 0.06 & 0.05 & 1.24 & 0.03 \\
$\mathbf{C}$ & 0.10 & 0.09 & 2.24 & 0.05 \\
$\mathbf{D}$ & 0.02 & 0.13 & 0.60 & 0.03 \\
E & 0.02 & 0.06 & 1.00 & 0.06 \\
WHO/FAO Limit & 0.03 & 0.10 & 1.31 & 0.03 \\
\hline
\end{tabular}

Table 4

Estimated daily Intake of Heavy metals (DIM) from Bread for Children and Adults in $m g / k g$

\begin{tabular}{|c|c|c|c|c|c|c|c|c|}
\hline \multirow[t]{2}{*}{ Brands } & \multicolumn{5}{|c|}{ DIM (mg/kg) For Children } & \multicolumn{3}{|c|}{ DIM (mg/kg) for Adult } \\
\hline & $\mathbf{P b}$ & $\mathrm{Cd}$ & $\mathbf{Z n}$ & $\mathrm{Cr}$ & $\mathbf{P b}$ & Cd & $\mathbf{Z n}$ & $\mathrm{Cr}$ \\
\hline $\mathbf{A}$ & 0.06 & 0.05 & 1.24 & 0.03 & 0.086 & 0.071 & 1.771 & 0.043 \\
\hline B & 0.10 & 0.09 & 2.24 & 0.05 & 0.143 & 0.129 & 3.200 & 0.071 \\
\hline $\mathbf{C}$ & 0.02 & 0.13 & 0.60 & 0.03 & 0.029 & 0.186 & 0.857 & 0.043 \\
\hline D & 0.02 & 0.06 & 1.00 & 0.06 & 0.029 & 0.086 & 1.429 & 0.086 \\
\hline $\mathbf{E}$ & 0.03 & 0.10 & 1.31 & 0.03 & 0.043 & 0.143 & 1.871 & 0.043 \\
\hline
\end{tabular}

The concentration levels of some heavy metals such as $\mathrm{Pb}, \mathrm{Cd}, \mathrm{Cr}$ and $\mathrm{Zn}$ in the five different brand samples of bread locally produced in Maiduguri, Borno State (samples A, B, C, D and E), were determined using atomic absorption spectrophotometer. The results are tabulated (Table 3 and 4). From the results obtained $\mathrm{Zn}$ has the highest concentration in all the bread samples. Zinc is one of the most ubiquitous of the essential elements necessary for the function of a large number of metalloenzymes having the highest concentration in all the analyzed bread samples (Beliles, 1994). The variation of the metals in samples A and B as shown in Table 2 is in the order, $\mathrm{Zn}>\mathrm{P} \mathrm{b}>\mathrm{Cd}>\mathrm{Cr}$ with $\mathrm{Cr}$ having the lowest value $(0.03$ $\mathrm{mg} / \mathrm{L}, 0.05 \mathrm{mg} / \mathrm{L}$ respectively). The order of concentration in sample $\mathrm{C}$ and $\mathrm{D}$ is $\mathrm{Zn}>\mathrm{Cd}>$ $\mathrm{Cr}>\mathrm{Pb}$ and $\mathrm{Zn}>\mathrm{Cr}>\mathrm{Cd}>\mathrm{Pb}$ respectively with $\mathrm{Pb}$ having the lowest concentration $(0.02$ $\mathrm{mg} / \mathrm{L}$ ). In sample $\mathrm{E}$, the order is $\mathrm{Zn}>\mathrm{Cd}>\mathrm{Cr}>\mathrm{Pb}$ with $\mathrm{Cr}$ and $\mathrm{Pb}$ having the lowest value $(0.03 \mathrm{mg} / \mathrm{L})$. The results obtained from the analysis are below the permissible level recommended by WHO/FAO, therefore, this indicates that the consumption of the studied brands of bread pose no health risk or hazard. Most heavy metals are usually toxic metals and 
are mostly carcinogenic in nature as tend to accumulate in visual and sensory organs of human beings leading to cancer. Thus, bread meant for consumption must be below WHO standard limit for bread safety.

\section{CONCLUSION}

Samples of chocolate brands and bread were analyzed for levels of some heavy metals $(\mathrm{Pb}$, $\mathrm{Cd}, \mathrm{Zn}$, and $\mathrm{Cr}$ ). The results of this studies revealed that the studied heavy metals were found to be below the FAO/WHO standards. This implies that the consumption of the studied brands of bread pose no health risk or hazards.

\section{References}

Akan, J. C., Abdulrahman, F. I., Sodipo, O. A., Ochanya, A. E., \& Askira, Y. K. (2010). Heavy metals in sediments from River Ngada, Maiduguri Metropolis, Borno State. Nigeria Journal of Environmental Chemistry and Ecotoxicology, 2(9), 131-140.

Beliles, R. P. (1994). The Metals in Patty's Industrial Hygiene and Toxicology ( $4^{\text {th }}$ Edn.). Vol. 2, part c. Wiley \& Son, Inc.

Dias, A. R. M., \& Wickramasinghe, I. (2016). Determination of Toxic Metals in Chocolate Confectionery Wrappers used by the Chocolate Manufacturers in Sri lanka and its Migration to Chocolates under Different Storage Conditions, International Journal of Science and Research, 5(1), 352-357.

Hashemi, M., Salahi, T., Aminzare, M, Raeisi, M., \& Afshari, A. (2017). Contamination of Toxic Metals in Various Foods in Iran: A Review, Journal of Pharmaceutical Sciences and Research, 9(10), 1692-1697.

Ikem, A., \& Egiebor, N. O. (2005). Assessment of Trace Elements in Canned Fishes (mackerel, tuna, salmon, sardines and herrings) Marketed in Georgia and Alabana (United States of America). Journal of Food Composition and Analysis, 18(8),771787.

Iwegbue, C. M. A. (2011). Concentration of Selected Metals in Candies and Chocolates Consumed in Southern Nigeria. Food Additives and Contaminants, part B 4(1), 2227.

Lanre-Iyanda, T. Y., \& Adekunle, I. M. (2012). Assessment of Heavy Metals and Their Estimated Daily Intakes from Two Commonly Consumed Foods (Kulikuli and Robo) Found in Nigeria, African Journal of Food, Agriculture, Nutrition and Development, 12(3), 6156-6169.

Ochu, J. O., Uzairu, A., Kagbu, J. A., Gimba, C. E., \& Okunola, O. J. (2012). Evaluation of Some Heavy Metals in Imported Chocolate and Candies Sold in Nigeria, Journal of Food Research, 1(3), 169-177.

Radojevic, M., \& Bashkin, V. N. (1999). "Practical Environment analysis", Royal Society of Chemistry, Cambridge, 466.

Shahryari, R., \& Mollasadeghi, V. (2011). Introduction of Two Principle Components for Screening of Wheat Genotypes under End Seasonal Drought, Advances in Environmental Biology, 519-523

WHO. World Health Organization. (1983). Environmental Health Criteria, vol. 165, Geneva, 1995. 